\title{
Pemberian Abdominal Stretching Exercise Terhadap Nyeri Disminore Pada Remaja
}

\author{
Nurul Devi Ardiani ${ }^{1}$, Fakhrudin Nasrul Sani ${ }^{2}$ \\ ${ }^{1}$ STIKes Kusuma Husada Surakarta, email: mama.ayla.zahra@gmail.com \\ ${ }_{2}^{2}$ STIKes Kusuma Husada Surakarta, email: fakhrudin_ns@ymail.com
}

\begin{abstract}
Abstrak. Dismenorea atau nyeri menstruasi di hari pertama sering dialami oleh wanita. Nyeri disminorea juga dapat berlangsung sebelum sampai beberapa hari selama menstruasi. Dismenorea yang dirasakan oleh remaja sangat berdampak jika tidak ditangani, hal ini dapat mengganggu aktivitas sehari-hari. Penanganan dismenorea pada remaja diperlukan untuk mencegah dampak negatif yang dapat timbul secara berkepanjangan. Penatalaksanaan nyeri disminorea secara nonfarmakologi salah satunya adalah pemberian Abdominal Stretching Exercise. Tujuan dari penelitian ini adalah untuk mengetahui efektifitas pemberian Abdominal Stretching Exercise pada remaja dengan nyeri disminorea di SMPIT Nur Hidayah Surakarta.Jenis Penelitian ini adalah kuantitatif menggunakan desain Quasi Eksperimental dengan pre-post test without control. Sampel penelitian sebanyak 30 siswi SMPIT Nur Hidayah Surakarta. Uji normalitas data dilakukan dengan menggunakan Shapiro Wilk dengan hasil distribusi data tidak normal sehingga analisa data dilakukan dengan menggunakan uji Wilcoxon. Abdominal stretching exercise efektif menurunkan nyeri disminore pada siswi di SMPIT Nur Hidayah Surakarta. Abdominal stretching exercise efektif menurunkan nyeri disminore pada siswi di SMPIT Nur Hidayah Surakarta. Hasil uji statistik dilakukan sebelum dan sesudah tindakan Abdominal Stretching Exercise pada siswi dengan nyeri disminorea. Analisa data dengan menggunakan Uji Wilcoxon diperolah nilai sig 0,00 yang berarti nilai $\mathrm{p}<0,05$, dapat disimpulkan terdapat pengaruh Abdominal Stretching Exercise terhadap nyeri disminorea di SMPIT Nur Hidayah Surakarta
\end{abstract}

Kata kunci: Abdominal Stretching Exercise, Nyeri Disminore, remaja

\section{Provision of Abdominal Stretching Exercise Against Disminore Pain in Adolescents}

\begin{abstract}
Dysmenorrhoea or menstrual pain is often experienced by women. It's pain arising from menstruation before or during menstruation, its occurring on the first day to several days during menstruation. Dysmenorrhoea felt by adolescents is very impactful if not treated because it causes disruption of daily activities. Dysmenorrhoea in adolescents must be treated with appropriate measures to avoid from negative impacts that will arise prolonged. One of the non-pharmacological management of dysmenorrhoea pain is Abdominal Stretching Exercise. The present study aimed to determine the effectiveness of Abdominal Stretching Exercise in adolescents with dysmenorrhea pain at Nur Hidayah Surakarta Junior High School. This was a quantitative study using a Quasi Experimental design with pre-post test without control. The research involved 30 respondents of students of Nur Hidayah Surakarta Junior High School. Normality test were analyzed using Shapiro Wilk with result abnormal data distribution than data were analyzed using Wilcoxon test. The results of analysis abdominal stretching exercise was effective in reducing dysmenorrhea pain in female students at Nur Hidayah Surakarta Junior High School. Statistical test carried out before and after Abdominal Stretching Exercise on female students with disminorea pain. The data were analyzed using Wilcoxon test found a sig score of 0.00 results, and showed a p value of $<0.05$ so that it was concluded that Abdominal Stretching Exercise had an influence on dysmenorrhea pain in Nur Hidayah Surakarta Junior High School
\end{abstract}

Keyword: Abdominal Stretching Exercise, dysmenorrheal pain, teenager 


\section{Pendahuluan}

Masa remaja merupakan suatu fase perkembangan yang dilalui oleh setiap kehidupan seseorang. Masa ini sering disebut sebagai masa peralihan dari fase perkembangan anak ke fase perkembangan dewasa yang ditandai dengan perkembangan fisik, mental, emosional, dan sosial (Nuraeni, 2017). Perubahan pertama terdapat pada aspek biologis, dan salah satu tandanya bagi remaja putri yaitu mulai mengalami menstruasi. Menstruasi menandakan kematangan organ dari remaja putri yang mulai matang sehingga siap untuk hamil atau atau berada dalam fase reproduksi (Harahap\&Lismarni, 2013). Menstruasi merupakan perdarahan periodik normal yang keluar dari uterus dan merupakan tanda kematangan fungsi fisiologis pada wanita. Haid merupakan proses katabolisme dan terjadi di bawah pengaruh hormon hipofisis dan ovarium (Benson, 2009).

Beberapa remaja mengalami gangguan saat menstruasi yaitu nyeri yang disebut dengan dismenorea. Dismenorea atau nyeri menstruasi adalah nyeri yang timbul akibat menstruasi baik di hari pertama ataupun sebelumnya sampai beberapa hari selama menstruasi. Jenis Dismenorea pada wanita umumnya adalah disminorea fungsional (normal) yang terjadi pada hari pertama atau menjelang hari pertama akibat dari penekanan pada kanalis servikalis (leher rahim), danakan menghilang seiring hariberikutnya menstruasi. Dismenorea nonfungsional

(abnormal) mengakibatkan rasa nyeri hebat terus menerus baik sebelum, sepanjang menstruasi, maupun sesudahnya. Jika hal ini terjadi, bisa dicurigai atau mengarah ke endometriosis atau kista ovarium (Hasnah \& Harmina, 2017) .

Rata-rata lebih dari $50 \%$ perempuan di setiap negara mengalami nyeri menstruasi. Pada penelitian Lestari
(2008) menunjukkan prevalensi dismenorea di Indonesia sebesar 64,25 persen yang terdiri dari 54,89 persen dismenorea primer dan 9,36 persen dismenorhea sekunder.

Penatalaksanaan dismenorea bisa dilakukan dengan cara farmakologis dan non farmakologis. Cara nonfarmakologis diantaranya istirahat yang cukup, mengkonsumsi minuman hangat berkalsium tinggi, relaksasi nafas dalam atau yoga, distraksi nyeri, melakukan aktivitas fisik seperti olah raga,bersepeda dan senam aerobik, akupresure, mandi air hangat, kompres dengan kantong air panas (buli-buli)/ hangat pada bagian yang nyeri, dan abdominal stretching exercise (Murtiningsih \& Karlina, 2015). Penatalaksanaan nyeri disminorea secara nonfarmakologis sangat diperlukan dengan alasan biaya terjangkau, memanfaatkan pemberdayaan anggota keluarga,tidak mempunyai efek samping, dan bisa dilakukan secara mandiri

Abdominal stretching exercise merupakan suatu latihan peregangan otot terutama pada perut yang dilakukan selama 10-15 menit. Latihan ini diberikan dengan tujuan meningkatkan kekuatan otot, daya tahan, dan fleksibilitas, sehingga diharapkan dapat mengurangi nyeri haid (Arifiyani, 2016). Abdominal stretching exercise dapat meningkatkan kadar endorphin oleh otak akibat latihan fisik. Sehingga latihan fisik dapat sebagai analgesik spesifik untuk jangka pendek yaitu menurunkan rasa sakit (Yuliana, 2013).

\section{Metode}

Jenis Penelitian ini adalah kuantitatif menggunakan desain quasi experiment dengan pre-post test without control yang dilakukan dengan melakukan suatu intervensi pada satu kelompok tanpa pembanding. Penelitian ini untuk mengetahui pengaruh Abdominal 
stretching execise terhadap nyeri disminorea pada Remaja Di SMPIT Nur Hidayah Surakarta.

Populasi dalam penelitian ini yaitu Siswi SMPIT Nur Hidayah Surakarta sebanyak 123 orang dengan jumlah sampel 30 siswi diambil teknik purposive sampling. Waktu pengambilan kasus dilakukan bulan Mei - Agustus 2019.

Data penelitian diambil dengan mengukur skala nyeri disminorea sebelum diberikan Abdominal Stretching exercise kemudian diberikan tindakan Abdominal Stretching exercise dan dilakukan pengukuran skala nyeri setelah diberikan Abdominal Stretching exercise. Analisis data dilakukan menggunakan uji Wilxocon.

Pemberian tindakan Abdominal Stretching exercise diberikan sebelum siswi mengalami menstruasi sehingga tindakan ini bisa dilakukan saat siswi merasakan disminorea.

\section{Hasil Penelitian}

1. Skala Nyeri Disminore Pada Siswi Saat menstruasi

Tabel 1 Skala Nyeri Disminorea Pada Siswi Saat Menstruasi

\begin{tabular}{|c|c|c|}
\hline Karakteristik nyeri & Jumlah & $\begin{array}{c}\text { Prosenta } \\
\text { se }\end{array}$ \\
\hline \multicolumn{3}{|c|}{ Sebelum Abdominal Stretching } \\
\hline Tinggi & 0 & 0 \\
\hline Sedang & 22 & 73,3 \\
\hline Rendah & 8 & 26,7 \\
\hline Total & 30 & 100 \\
\hline \multicolumn{3}{|c|}{ Setelah Abdominal Stretching } \\
\hline Tinggi & 0 & 81,8 \\
\hline Sedang & 7 & 23,3 \\
\hline Rendah & 23 & 76,7 \\
\hline Total & 30 & 100 \\
\hline
\end{tabular}

Berdasarkan table 5.1 karakteristik nyeri disminore sebelum dilakukan abdominal stretching exercise dengan kategori ringan sebanyak 8 siswa dengan presentase $26,7 \%$ dan nyeri disminore dengan kategori sedang sebanyak 22 siswa dengan presentase $73,3 \%$. Nyeri disminorea setelah dilakukan abdominal stretching exercise dengan kategori ringan sebanyak 23 siswa dengan presentase $76,7 \%$ dan nyeri disminore dengan kategori sedang sebanyak 7 siswa dengan presentase $23,3 \%$.

2. Analisis pengaruh Abdominal Stretching exercise terhadap nyeri disminore

Tabel 2 Analisis Pengaruh Abdominal Stretching Exercise terhadap Nyeri Disminorea

\begin{tabular}{lc}
\hline & $\begin{array}{c}\text { Pe-post } \\
\text { Kel perlakuan }\end{array}$ \\
\hline $\mathrm{Z}$ & $-4,868^{\mathrm{a}}$ \\
Asymp. Sig. (2-tailed) &, 000 \\
\hline
\end{tabular}

Berdasarkan tabel 5.2 hasil analisa data menggunakan uji wilcoxon menunjukkan nilai $(p=0,000)$ dengan nilai $\mathrm{p}<0.05$. Dari hasil tersebut dapat disimpulkan bahwa terdapat pengaruh abdominal Stretching exercise terhadap nyeri disminorea.

\section{Pembahasan}

Nyeri pada (disminore) adalah normal, selama disminore terjadi kontraksi rahim yang diakibatkan oleh kadar prostaglandin yang meningkat sehingga menyebabkan vasospasme arteriol uterin dan iskemia serta kram di bagian abdomen bawah yang merangsang terjadinya nyeri saat mestruasi. Nyeri saat dismenore membuat perempuan tidak bisa beraktivitas secara normal dan memerlukan obat pereda sakit. Hal ini menyebabkan kualitas hidupnya menurun.

Jika dismenore terjadi pada siswi maka bisa menyebabkan siswi tidak bisa mengikuti pembelajaran dengan baik dan menyebabkan penurunan motivasi belajar disebabkan karena nyeri yang dirasakan. Hal ini perlu ditindaklanjuti supaya disminore agar tidak mengganggu 
aktivitas (Ningsih, dkk, 2013). Banyak cara yang dilakukan remaja untuk mengatasi disminorea yaitu farmakologis dan nonfarmakologis. Manajemen nonfarmakologis lebih baik digunakan karena tidak menimbulkan efek samping seperti manajemen farmakologis. Salah satu cara yang bisa dilakukan adalah dengan melakukan abdominal stretching exercise.

Hasil penelitian ini didapatkan hasil bahwa abdominal stretching exercise bisa menurunkan nyeri disminore. Hasil sesuai dengan penelitian Ningsih, dkk, 2013 bahwa exercise efektif dalam menurunkan nyeri haid (dismenore primer). Exercise akan menghasilkan peningkatan hormone endorphin 4-5 kali dalam darah yang berfungsi sebagai penenang alami sehingga menimbulkan rasa nyaman. Peningkatan endorphin dapat menurunkan rasa nyeri dapat mengurangi rasa nyeri saat terjadinya kontraksi. Peningkatan endorphine memberikan efek penurunan nyeri, peningkatan daya ingat, peningkatan nafsu makan, peningkatan seksual, tekanan darah dan pernafasan. Latihan efektif dalam menurunkan nyeri disminorea.

Abdominal stretching pada remaja disminore dapat meningkatkan kekuatan otot, daya tahan dan fleksibilitas otot, meningkatkan kebugaran, meningkatkan daya tangkap, meningkatkan mental dan relaksasi fisik, mengurangi ketegangan otot, mengurangi nyeri otot (kram), dan mengurangi nyeri saat menstruasi (Fauziyah, 2015).

Menurut Sormin (2014) mengatakan bahwa senam disminore dapat menurunkan skla disminore dan gejala peyertanya. Efek terhadap tubuh adalah terasa rileks serta relaksasi pada otot uterus yang menyebabkan kontraksi uterus berkurang. Senam disminore juga dapat meningkatkan aliran darah dipanggul dan merangsang peningkatan produksi hormon endorphin didalam tubuh yang diproduksi oleh otak. Pelepasan hormon endorphin didalam tubuh memberi dampak pada penurunan skala nyeri dikarenakan hormon endorphin merupakan analgesik nonspesifik.

Saat disminore beberapa otot mengalami ketegangan. Abdominal stretching yang dilakukan saat dismenore dapat merilekskan otot-otot yang mengalami ketegangan. Gerakan yang dilakukan berfokus pada bagian panggul sehingga menyebabkan otot-otot uterus yang tegang mengalami relaksasi dan nyeri pun akan berkurang. Senam disminore mempunyai dampak yang lebih baik dalam penurunan nyeri daripada melakukan istirahat saja, sehingga jika nyeri berkurang maka mood akan stabil dan menimalkan depresi.

Hasil penelitian Hidayah, dkk (2017) menyatakan bahwa Abdominal Stretching Exercise adalah latihan fisik yang dapat diberikan dengan tujuan penurunan disminorea saat menstruasi. Fokus gerakannya yakni peregangan otot abdomen yang dilakukan 10-15 menit untuk meningkatkan kekuatan otot, daya tahan dan fleksibilitas otot sehingga nyeri disminorea berkurang. Latihan ini merupakan solusi yang dapat dilakukan mandiri dan berdampak lebih rendah dibandingkan dengan mengkonsumsi obat nonfarmakologis yang akan menimbulkan efek pada tubuh jika dikonsumsi lama.

\section{Simpulan}

Karakteristik nyeri disminore paling banyak sebelum dilakukan abdominal stretching exercise dengan kategori sedang sebanyak presentase $73,3 \%$ Nyeri disminorea paling banyak setelah dilakukan abdominal stretching exercise dengan kategori ringan sebanyak 76,7\%.

Berdasarkan hasil analisa data menggunakan uji wilcoxon menunjukkan 
nilai $(p=0,000)$ dengan nilai $p<0.05$. Dari hasil tersebut dapat disimpulkan bahwa terdapat pengaruh abdominal Stretching Exercise terhadap nyeri disminorea pada siswi di SMPIT Nur Hidayah Surakarta.

\section{Saran}

Perlu dilakukan penelitian lebih lanjut tentang penatalaksanaan dalam penurunan nyeri disminorea dengan tindakan lain. Melakukan kerjasama dengan pihak sekolah untuk berkolaborasi dengan petugas kesehatan untuk implementasi lebih lanjut.

\section{Daftar Pustaka}

Andira, Dita. (2010). Seluk Beluk Kesehatan Reproduksi Wanita.Yogyakarta : Plus Books Anisa M, 2015. The Effect Of Exercises On Primary Dysmenorrhea. J MAJORITY Volume 4 Nomor 2 Januari 2015

Calis, Karim Anton 2011. Dysmenorrhea. Available from: http://emedicine.medscape.com/article /253812-overview

Hasnah \& Harmina, 2017. Efektifitas Terapi Abdominal Stretching Exercise Dengan Semangka Terhadap
Disminorhea. Journal Of Islamic Nursing Volume 2 Nomor 1, Juli 2017 Lestari, dkk. 2010. Gambaran Dismenorea Pada Remaja Putri Sekolah Menengah Pertama Di Manado. Sari Pediatri Vol.12 No. 2 Agustus 2010

Manuaba, IBG. 2009. Memahami Kesehatan Reproduksi Wanita. Jakarta: EGC

Murtiningsih \& Karlina, 2015. Penurunan Nyeri Dismenorea Primer melalui Kompres Hangat pada Remaja. http://jkp.fkep.unpad.ac.id/index.php/ jkp/article/viewFile/104/100 Volume 3 Nomor 2 Agustus 2015

Thermacare. 2010. Abdominal Stretching Exercise for Menstrual Pain. http://www.chiromax.com/media/abst retch.pdf

Wong,D.L,Hockenberry,M,Wilson,D,Wi nkelstein,M,L.,Schwartz,P.(2009). Wo ng's Essentials Of Pediatric Nursing. 6 th.st.Louis,Missouri: Mosby 